\title{
Magnetic resonance imaging of molecular transport in living morning glory stems
}

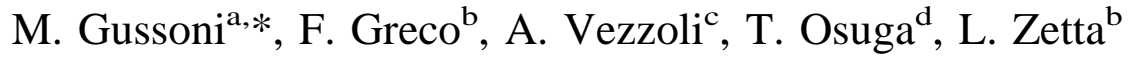 \\ ${ }^{a}$ Università di Milano, Dipartimento di Scienze e Tecnologie Biomediche, Milano, Italy \\ ${ }^{\mathrm{b}}$ Istituto di Chimica delle Macromolecole, CNR, Milano, Italy \\ ${ }^{\mathrm{c} C N R, ~ L . I . T . A ., ~ S e z i o n e ~ d i ~ F i s i o l o g i a, ~ S e g r a t e ~(M I), ~ I t a l y ~}$ \\ ${ }^{\mathrm{d}}$ Faculty of Science Chiba University, Yayoi, Inage, Chiba 263, Japan
}

Received 7 April 2001; received in revised form 18 October 2001; accepted 18 October 2001

\begin{abstract}
MRI was applied to investigate the transport pathways in Morning Glory plant stems. The study was carried out on living plants without affecting their integrity. The architecture of a dicotyledonous plant was deeply characterized: the root system structure and the vascular bundle location were identified, the presence of central voids caused by cell maturation and loss were observed in the stem. Molecular transport components were recognized, by observing the concentration profile of a tracer, which changed with time after its absorption by the plant roots. MRI analysis revealed the presence of an axial transport as the progress of the tracer front through the vascular bundles and a radial molecular transport from the vascular bundles toward the surface of the stem. As a result, the tracer molecular transport formed the parabolic tracer front (PTF). A model was built up through the analysis of the PTF that consisted of an axial front at the peak position and a radial front at the width of the parabolic tail. PTF analysis revealed differences between the tracer transport velocities in the axial and the radial directions in the plant stem. The model revealed that the width of the parabolic tail reflected the magnitudes of diffusion and permeation of the tracer in the plant stem. (c) 2001 Elsevier Science Inc. All rights reserved.
\end{abstract}

Keywords: Magnetic resonance imaging; Molecular transport; Contrast agent; Morning Glory (Pharbitis nil) stem; Vascular bundle

\section{Introduction}

Water transport through plants, one of the most important physiological variables related to plant growth and reproduction, has been extensively studied [1]. Recently a model has been proposed for the movement of water across roots [2]. Although many techniques are available to study water and molecular transport, few are non-destructive. Nuclear Magnetic Resonance (NMR) has been widely applied to the study of plant materials [3-6]. By means of ${ }^{1} \mathrm{H}$ NMR, the relaxation properties of tissue water were determined in order to investigate water distribution and water exchange in plant cell compartments [7,8]. The application of the NMR imaging technique (MRI) to plants allowed functional images to be acquired capable of giving simultaneously anatomic and spatially defined physiological information. MRI offers the advantage, over other methods such as light

\footnotetext{
* Corresponding author. Tel.: +1-39-022-642-3302; fax: +1-39-27064-3557.

E-mail address: Maristella.Gussoni@unimi.it (M. Gussoni).
}

microscopy, that image information is available from the surface as well as from the interior of the examined object without sample damage or destruction. Therefore MRI can be used to identify and localize the major constituents and structural details of seeds, fruit or plant organs. Moreover the non-destructive and non-invasive nature of this method offers the possibility of monitoring time dependent changes of variables by collecting repeated images on a single intact sample. Up to now MRI has been widely adopted to study plant morphology and development of seeds and fruits [9], plant histochemistry [10], differences in water content in plant stems [11], water and lipid content and distribution in fruits [12] and seeds [13]. Plant characteristics could be determined by both image contrast and relaxation times. Differences in ${ }^{1} \mathrm{H}$ relaxation times between vascular bundle and surrounding tissues were exploited to image pattern of transport in different plant specimens [14]. Therefore MRI provides one of the most powerful tools for studying water and molecular transport inside plants. Molecular transport in plants is classified into the macroscopic water flow, which is the axial water transport through the vascular tissue 
in the stem, and the microscopic molecular motions, which are diffusion and permeation inside and across cells in the plant tissue. Paths of flow could be monitored either directly from flow measurements $[15,16]$, or through the use of tracers that acted as contrast agents. A non-invasive measurement of xylem and phloem water flow in castor bean seedlings by MRI has been proposed [17]. A previous work with NMR spectroscopy has demonstrated that Gadolinium $(\mathrm{Gd})$ both chelated and unchelated could enter corn roots and reach the symplast [18]. Permeation of water molecules across plant cell compartments was measured using ${ }^{1} \mathrm{H}$ relaxation times by tracing the transport of $\mathrm{Mn}^{2+}$ paramagnetic ions, which have the effect of enhancing the proton relaxation rates of the water bound to them $[7,19]$.

The kinetics of the uptake of $\mathrm{D}_{2} \mathrm{O}$ instead of water by plants was followed by monitoring the loss of the proton water signal due to the wash out of the water, as well as by directly imaging the deuterium signal [20]. Moreover, MRI revealed the spatial variation of the water diffusion coefficients in plant tissues [15,21] and in germinating seeds [22].

In the present work MRI was used to investigate molecular transport in living plant stems by following the uptake kinetics of tracer molecules. From the experiments collected on an intact plant growing in the magnet the tracer movement in the stem was clearly visualized. A model was built up and flow parameters calculated. In particular, the analysis of the tracer front revealed the presence of both axial and radial tracer transport mechanisms. The forces driving the molecular transport were identified and analyzed by the model, through the parabolic tracer front (PTF) formed by the tracer molecules.

\section{Materials and methods}

\subsection{Sample preparation}

Morning Glory (Pharbitis nil) seeds were imbibed and germinated on wet filter papers and hydroponically grown. Water medium was void of nutrients and the temperature and the relative humidity of the air surrounding the samples were kept controlled at $23^{\circ} \mathrm{C}$ and $50 \%$ respectively. After about 4 days the germinated seeds had four leaves, the diameter of the stem and the total height were about $2 \mathrm{~mm}$ and $50 \mathrm{~mm}$, respectively. Then a plant sample was carefully introduced into a $10 \mathrm{~mm}$ NMR tube that was kept open during the experiments (see Section 2.2). Fig. 1 shows the plant inside the tube at the end of an experiment, as it was placed into the MRI probe: the stem is located just within the radio-frequency coils (indicated in the figure) and the leaves result outside the coil sensitive volume, but inside the tube to allow the plant to transpire into the tube itself. Two solutions were prepared, containing the different tracers: Gadolinium (Gd) and Deuterium. As Gd tracer a $100 \mu \mathrm{M}$ aqueous solution of gadolinium-pentaaceticacid (GdDTPA; MW 743) (Magnevist, Shering, Germany) was pre-

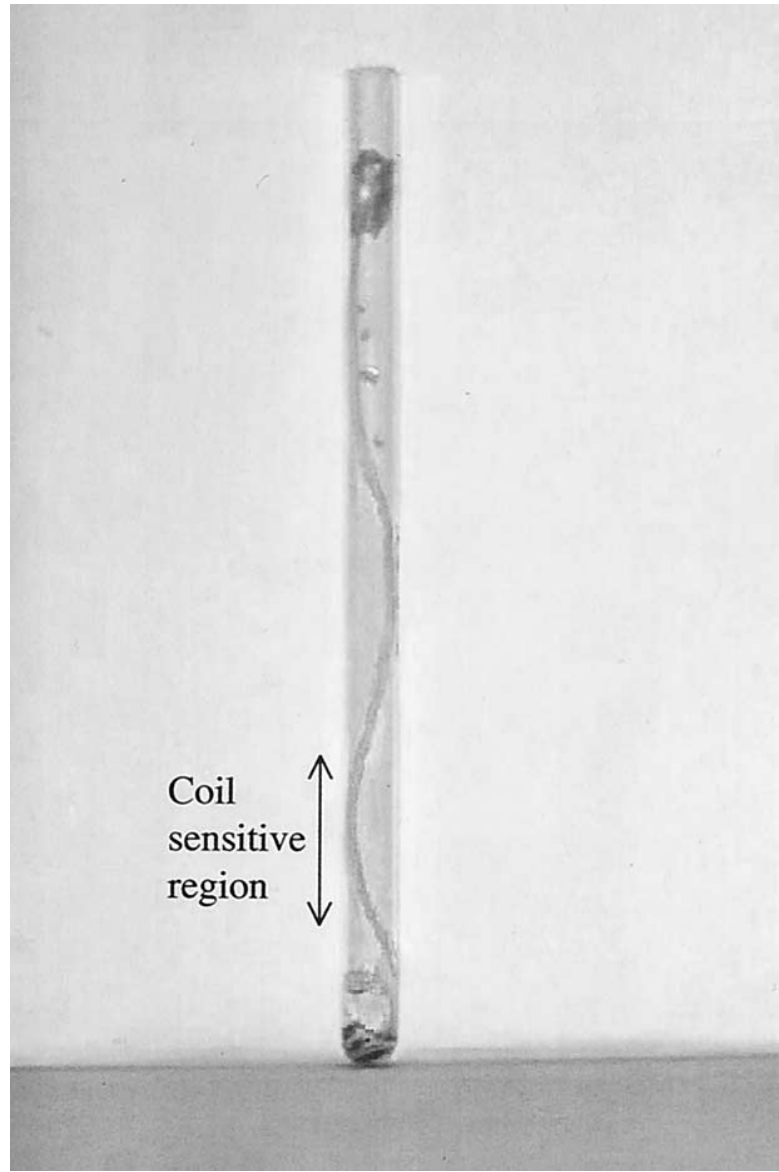

Fig. 1. Photograph of a living Morning Glory plant sample put into a 10 $\mathrm{mm}$ uncapped NMR tube. The amount of pure water visible at the bottom of the tube allows the plant to continue to transpire and to grow. The r.f. coils are indicated on the left side so that the leaves stay inside the tube but outside the sensitive region of the coils. The plant region to be studied is selected by varying the depth of the NMR tube into the probe-head. Drops of condensed water transpired by the leaves are visible on the walls of the tube.

pared [23]. As Deuterium tracer, a pure $\mathrm{D}_{2} \mathrm{O}$ solution (99.8\% isotopic purity) (Merck, Germany) was employed. At the time $\mathrm{t}=0$, the roots of the plant sample were immersed in a known amount of tracer solution $(1 \mathrm{ml}$ of $\mathrm{D}_{2} \mathrm{O}$ or $0.5 \mathrm{~mL}$ of Gd-DTPA respectively) located at the bottom of the NMR tube. The temperature of the inside of the NMR tube was kept at $23^{\circ} \mathrm{C}$, the relative humidity at the beginning of the experiment was $50 \%$. Extra sources of illumination were not used.

\subsection{MRI experiments}

All MRI experiments on Morning Glory plant were carried out on a 4.7 Tesla Bruker AM WB superconducting magnet (Bruker, Karlsruhe, Germany) with a $9 \mathrm{~cm}$ diameter vertical bore, equipped with a probe-head tuned at the ${ }^{1} \mathrm{H}$ resonance frequency $(200.13 \mathrm{MHz})$, a $15 \mathrm{~mm}$ insert, accepting $10 \mathrm{~mm}$ NMR tubes. Orthogonal field gradient coils, built into the micro-imaging probe head, were capable of 
achieving gradients up to $50 \mathrm{G} / \mathrm{cm}$, with trigger pulses for switching the gradients of $5 \mu \mathrm{s}$. Since in this configuration the instrument was not provided with field frequency stabilization (lock channel), at the beginning of the experiment the field frequency was set on the water resonance frequency. MRI experiments were carried out employing a 2D spin-echo pulse sequence, standardly supplied by Bruker. Longitudinal $\left(90^{\circ}\right.$ tilted) and transverse spin echo images were acquired. Transverse images: $256 \times 256$ matrices; Field of view: $(\mathrm{FOV})=11 \mathrm{~mm}$; voxel resolution $43 \times 43 \times$ $3000 \mu \mathrm{m}^{3}$ with 8 averages so that the image was obtained in about $30 \mathrm{~min}$. Longitudinal images (no slice selection): $256 \times 256$ matrices; FOV $=40 \mathrm{~mm}$; planar resolution $156 \times 156 \mu \mathrm{m}^{2}$. Acquisition parameters were: spectral width of $33 \mathrm{kHz}$; recycle time (TR) of $1 \mathrm{~s}$. Thus all images were $T_{1}$ weighted in the same way. On the contrary the images were differently $T_{2}$ weighted, since a longer echo time is required to reach higher pixel resolution. Indeed all echo times resulted long, owing to the dead time required to stabilize the gradients $(1 \mathrm{~ms})$. Therefore all images were strongly $T_{2}$ weighted rather than $T_{1}$ weighted. Selective radio frequency pulses $2000 \mathrm{~Hz}$ bandwidth, Gaussian shaped, truncated at $5 \%$ level, were used. Other acquisition parameters are reported in the Figure Captions. Bio-effects of the steady magnetic field on the plant were neglected [24].

\section{Results and discussion}

\subsection{MRI of Morning Glory after germination}

\subsubsection{Plant morphology and development}

Water transport in most plants is achieved in a vascular bundle via a pumping mechanism that is driven mainly by an external force (water vapor pressure gradient) and internal forces that are osmotic gradients within the plant. The gradient of water vapor pressure creates a flow trough the plant and the loss of water by transpiration. It is well known that the external force makes a major contribution to the total water flow in transpiring plants [25]. In this respect, in order to study water transport, all external and internal forces driving water flow are not to be altered. Indeed, the cut made for obtaining a plant sample that has to be studied under a light microscope, interrupts the circulation of the water within the plant. A non-invasive and non-destructive method that does not affect the integrity of the whole plant is therefore required. MRI is particularly suited to study plant materials, as images can be obtained from an intact sample growing at constant environmental conditions in the bore of a superconducting magnet. Moreover stems are mostly indicated to study transports, owing to their linear continuity and longitudinal symmetry.

The present study was carried out on the stem of a living Morning Glory plant put in a $10 \mathrm{~mm}$ NMR tube with an amount of pure water to allow the plant to continue to grow.
The main anatomic features of Morning Glory plant were firstly studied in order to better understand the mechanisms of water transport upon tracer addition (see Sections 3.1.2 and 3.1.3). Through a series of transversal images, obtained at different plant levels, from the roots to the stem apex, the morphology of a dicotyledonous plant was recognized, distinguishing the various tissues that constitute the roots and the stem. The differences in image contrast were mainly due to the different water content of tissues, while dark regions were attributable to both rigidified tissues and/or voids. Figs. 2a, 2b and 2c report MRI images acquired on the intact plant sample. It should be pointed out that the images are of rather poor quality (in particular Figs. $2 b$ and $2 c$ ) due to the low pixel resolution and the thick slice chosen to obtain the images in a short experimental time (a few minutes). In fact, these images were acquired to get a preliminary overview by MRI confirming the expected taxonomy and to be sure that the plant sample was still under physiological conditions. For comparison, a series of optical micrographs of cross sections, obtained at about the same plant levels, are shown in Figs. 2a', 2b' and 2c'. Fig. 2a shows the transversal spin-echo section of a young root where the central bright vasculature appears surrounded by the parenchimal tissue. The same plant architecture appears in the corresponding optical image (Fig. 2a'). Figs. 2b and 2b' show images of a transverse section of the stem. In both of them, starting from the center, the pith parenchyma, the vascular tissue, the fibrous sheath, the cortical parenchyma, the epidermal tissue and the four vascular bundles, appearing bright in the MRI image (b) and dark in the optical one (b'), can be distinguished.

The distribution of the vascular tissue in a plant stem is known to be classified into three types: i) uniformly distributed throughout the cross section; ii) located between the surface and the central axis of the stem, and iii) concentrated on the central axis of the stem [26,27]. In the present sample, like in a dicotyledonous plant, the four vascular bundles, through which the water absorbed by the roots flows vertically upward, are located, as it would be expected, between the surface and the central axis of the stem in agreement with the type described in ii).

Figs. $2 \mathrm{c}$ and $2 \mathrm{c}$ ' show images of a transverse section close to the stem apex. The four vascular bundles are still visible, even if they are blurred due to the thick slice and the poor alignment of the image slice. At this stem level, the central pith parenchyma appears completely dark in the MRI image (Fig. 2c) and void in the optical section (Fig. $\left.2 c^{\prime}\right)$. These features indicate that cell maturation occurred with consequent cell loss. Optical images allow to estimate the size of parenchyma cells which is about $50 \times 70 \mu \mathrm{m}^{2}$. As well known, the vascular bundle in a dicotyledonous plant is composed of cells that are long and slender in the axial direction parallel to the plant stem. A lot of cells are supposed to constitute the vascular bundle since the diameter of a single cell, not measurable from the optical images $2 b^{\prime}$ and $2 c^{\prime}$, is reported to be about $50 \mu \mathrm{m}$ [6]. 

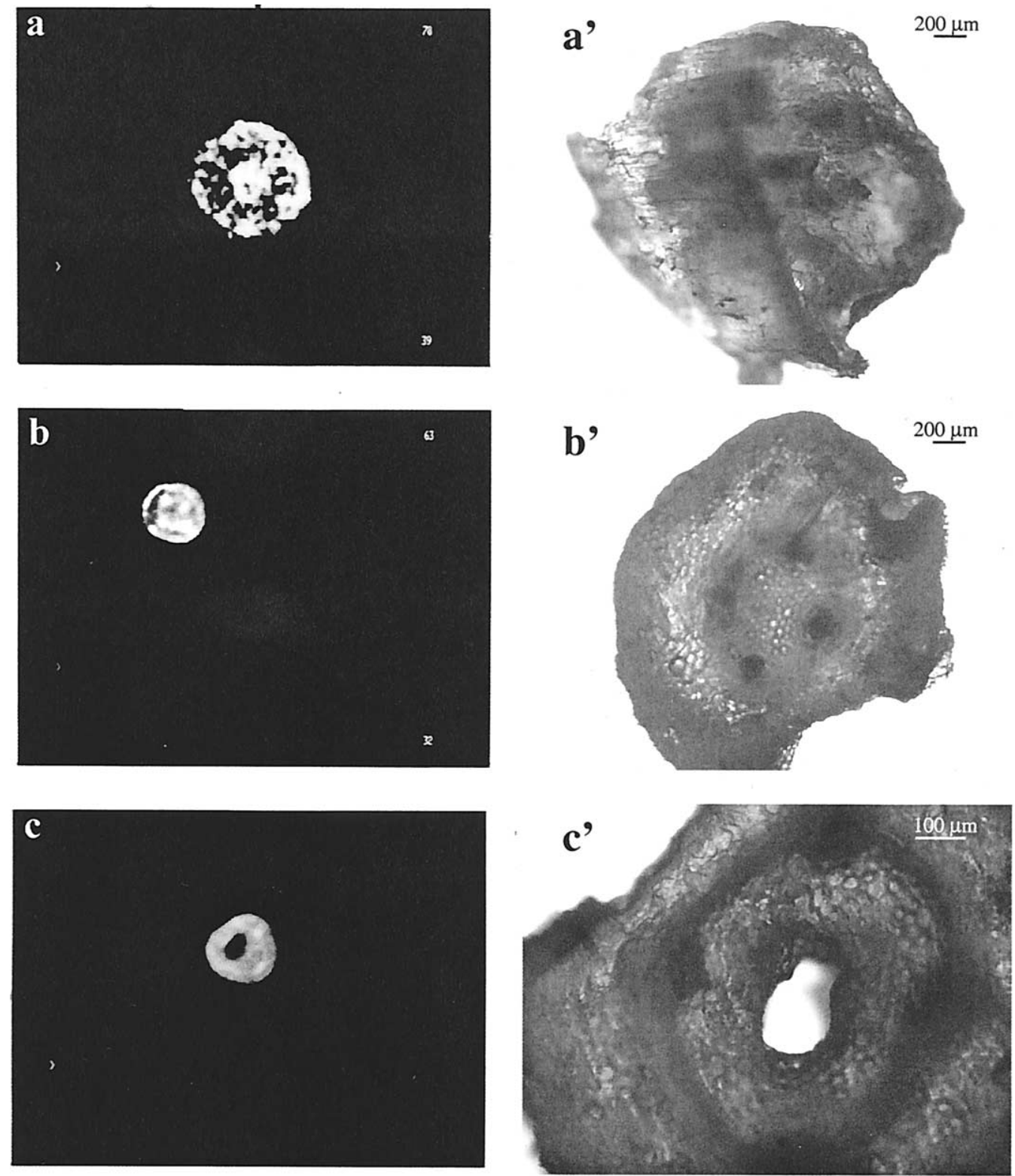

Fig. 2. Images collected at different levels of a Morning Glory plant: MRI spin-echo xy images of the intact sample (a-c); light microscopy cross-sections of a plant sample cut at about the same levels (a'-c'). The images show: (a and a'): the root system; ( $b$ and b'): a cross section of the stem with the four vascular bundles; (c and c'): a cross section of the stem toward the apex showing a void central pith parenchyma. Spin-echo xy images: (a): $256 \times 256$ matrix; FOV = $8 \mathrm{~mm} ; \mathrm{TE}=12.7 \mathrm{~ms} ; \mathrm{NE}=8 ; \mathrm{RG}=200$; voxel resolution: $31 \times 31 \times 3000 \mu \mathrm{m}^{3 ;} \mathrm{TR}=1 \mathrm{~s}$. (b) and (c): $128 \times 128 \mathrm{matrix} ; \mathrm{FOV}=9 \mathrm{~mm}$; $\mathrm{TE}=8.87$ $\mathrm{ms} ; \mathrm{NE}=8 ; \mathrm{RG}=200$; voxel resolution: $70 \times 70 \times 2000 \mu \mathrm{m}^{3 ;} \mathrm{TR}=1 \mathrm{~s}$.

\subsubsection{Heavy water transport in Morning Glory stem}

At the time $\mathrm{t}=0$ an intact plant sample of Morning Glory was inserted in the NMR tube where $1 \mathrm{~mL}$ of pure $\mathrm{D}_{2} \mathrm{O}$ solution had been located at the bottom. Starting from this time, the kinetics of the $\mathrm{D}_{2} \mathrm{O}$ uptake was followed for $30 \mathrm{~h}$. A series of both longitudinal (no slice selection) and transverse images were acquired to monitor the progression of the tracer front in the stem. The acquisition time of each image was about $30 \mathrm{~min}$ so that the images were collected every $30 \mathrm{~min}$. Fig. 3 shows the longitudinal xz spin-echo images of the plant sample in the NMR tube at two (Fig. 3a) and five hours (Fig. 3b) from the onset of the kinetics, respectively. The plant is placed in the tube as it appears in the sketch shown in the middle of the Figure. Looking at the sketch it can be observed the tracer amount put at the bottom of the NMR tube and the Morning Glory plant sample with roots, cotyledon and stem that appears folded up. All these, as located in the coil sensitive region, are, in principle, observable in the images too. On the contrary, the upper part of the stem and the leaves, located outside the coil sensitive region, are observable only in the sketch. In both of Figs. 3a and $3 b$ images the roots are not visible as they became dark upon $\mathrm{D}_{2} \mathrm{O}$ absorption. In both images, as well, the amount of $\mathrm{D}_{2} \mathrm{O}$ put at the bottom of the NMR tube 


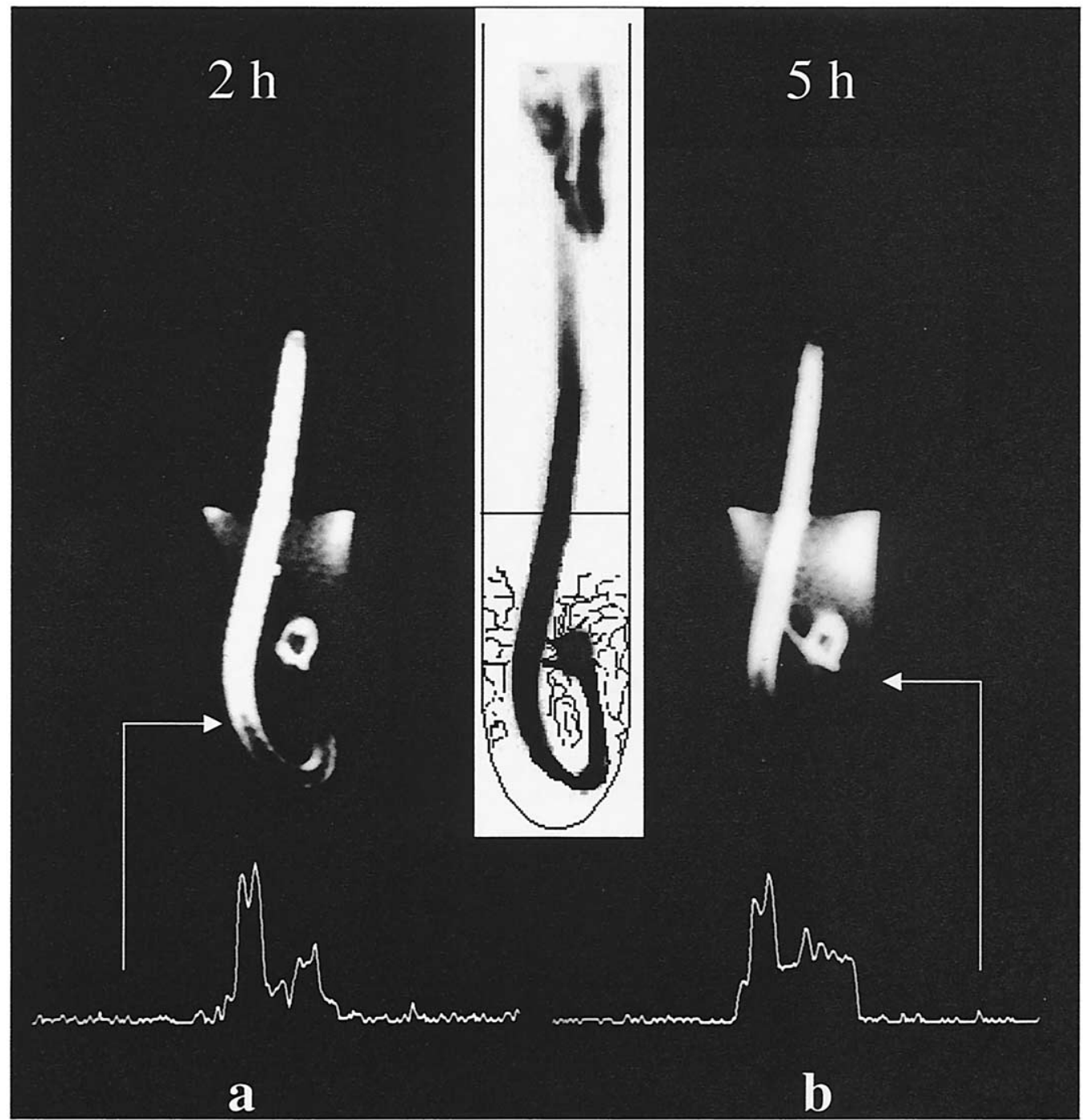

Fig. 3. Axial molecular transport component in the stem of a Morning Glory visualized by MRI by means of the $\mathrm{D}_{2} \mathrm{O}$ tracer absorbed by the roots. Increasing the time, the area of the initially present water (white region) decreases as the $\mathrm{D}_{2} \mathrm{O}$ tracer (dark region), absorbed by the roots, progresses upward throughout the stem. The condensed water related to plant transpiration is also visible (see text). The sketch drawn in the middle of the Figure shows the plant located in the NMR tube: cotyledon, roots, stem and leaves. A continuous line indicates the top of the $\mathrm{D}_{2} \mathrm{O}$ tracer content in the NMR tube in correspondence of the meniscus of the $\mathrm{D}_{2} \mathrm{O}$ in the images.

Spin-echo images collected during the kinetics of $\mathrm{D}_{2} \mathrm{O}$ uptake. Longitudinal xz images collected: (a) at two hours; (b) at five hours: $256 \times 256$ matrix; FOV = $40 \mathrm{~mm} ; \mathrm{NE}=8 ; \mathrm{RG}=16 ; \mathrm{TE}=12.7 \mathrm{~ms}$; voxel resolution: $156 \times 156 \times 10000 \mathrm{\mu m}^{3}$. At the bottom of the Figure, the transversal profiles related to the stem level indicated by the arrow are shown. They correspond to the top level reached by the $\mathrm{D}_{2} \mathrm{O}$ tracer at $2 \mathrm{~h}$ (a) and $5 \mathrm{~h}$ (b) respectively. The stem profile results on the left side as a double peak (see text).

appears as a dark region and its dark front in the stem is clearly distinguishable: in fact when the water initially present in the plant is washed out by the $\mathrm{D}_{2} \mathrm{O}$ uptake, a corresponding amount of the proton water signal is lost so that the stem image becomes dark. Moreover the images show that the cotyledon keeps being bright, since it does not absorb directly $\mathrm{D}_{2} \mathrm{O}$, owing to the impermeable structure of its membrane. In Fig. 3a, at the meniscus of the solvent (the corresponding level is shown in the sketch by a continuous line) two bright regions on either side of the meniscus are visible that are not attributable to the isotopic $\mathrm{D}_{2} \mathrm{O}$ impurity. This amount of condensed water, not yet completely mixed with the $\mathrm{D}_{2} \mathrm{O}$ solution, is a consequence of plant transpira- tion. In fact the leaves are well located inside the uncapped NMR tube and then exchanging with the surrounding ambient air (see both the sketch of Fig. 3 and Fig. 1).

At the same time $(2 \mathrm{~h})$, a spin-echo transverse image (Fig. 4a) was acquired at a stem level where, as shows up in the image of Fig. 3a, the $\mathrm{D}_{2} \mathrm{O}$ tracer front had not yet arrived. In the middle of Fig. 4, the same sketch of Fig. 3 indicates by an arrow where the images of Figs. $4 \mathrm{a}$ and $4 \mathrm{~b}$ were acquired: the level was the same for both images while the beginning of the acquisition was different $(2 \mathrm{~h}$ and $30 \mathrm{~h}$ respectively), as reported in the Figure. By comparing the images of Fig. 3a and Fig. 4a collected at the same time (2h), it can be pointed out that even if the tracer had not yet 


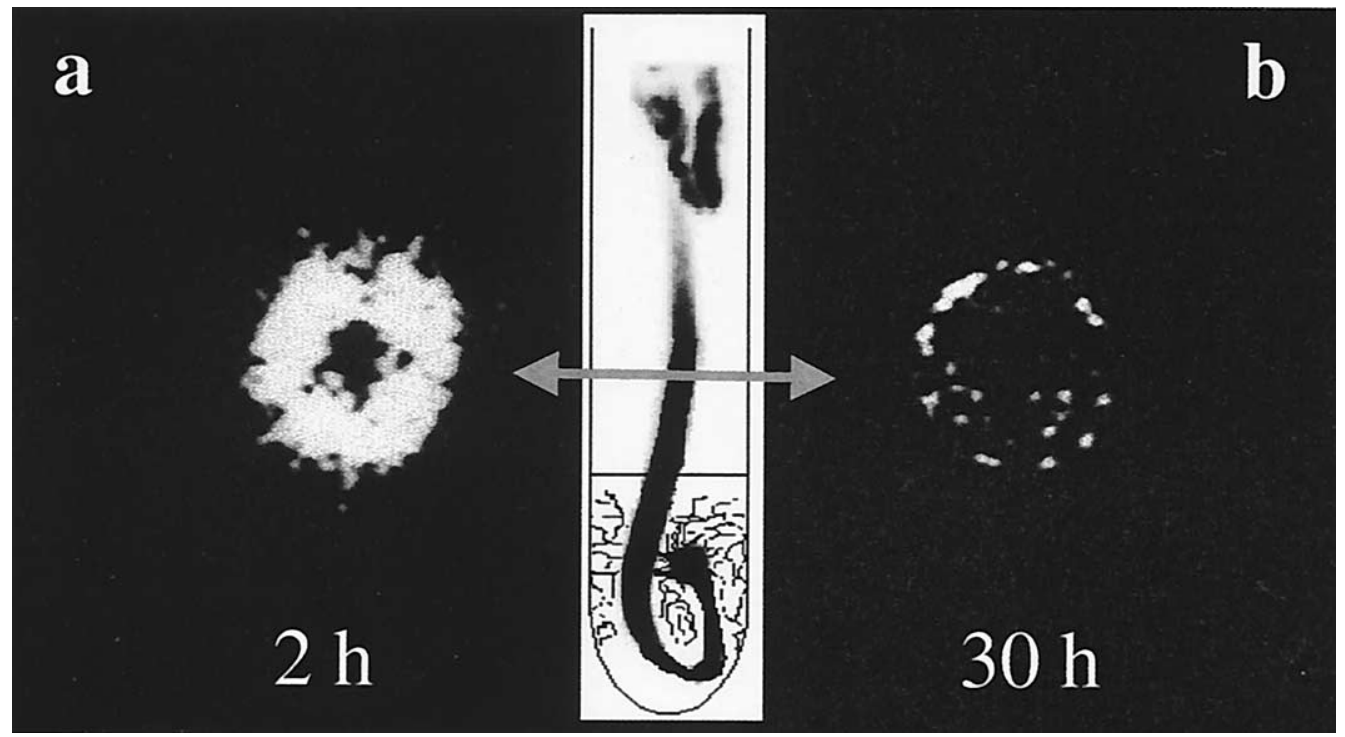

Fig. 4. Radial molecular transport component in the stem of a Morning Glory visualized by MRI by means of the $\mathrm{D}_{2} \mathrm{O}$ tracer absorbed by the roots. Increasing the time, the area of the initially present water (white region) decreases as the $\mathrm{D}_{2} \mathrm{O}$ tracer (dark region), absorbed by the roots, progresses radially throughout the stem tissue. The sketch in the middle of the Figure (the same of Fig. 3) shows the plant in the tube. Transverse xy images collected: at two hours (a) and at thirty hours (b) at the same stem level. A double arrow starting from the sketch indicates where in the stem the images were made. $256 \times 256$ matrix; $\mathrm{FOV}=11 \mathrm{~mm} ; \mathrm{TE}=12.71 \mathrm{~ms} ; \mathrm{NE}=8 ; \mathrm{RG}=200 \mathrm{in}(\mathrm{a}) ; \mathrm{RG}=800 \mathrm{in}(\mathrm{b})$; voxel resolution: $43 \times 43 \times 3000 \mu \mathrm{m}^{3}$

reached the stem level where the slice of Fig. 4a was taken, nevertheless this last image shows a surrounding bright region and a completely dark central part. These features suggest that the stem of this plant sample presented a void at the center, ascribable to cell loss (see also Fig. 2c) and confirm that water was still flowing in the vascular bundles.

At five hours from the beginning of the experiment, by comparing Figs. $3 \mathrm{a}$ and $3 \mathrm{~b}$ it can be observed the following: i) a significant increase of the bright region in the NMR tube; ii) an upward progress of the tracer front along the stem and iii) a wide enlargement of the dark region in the lower part of the tube. These two last findings suggest that both axial and radial components of $\mathrm{D}_{2} \mathrm{O}$ tracer transport were present. As well, the bright region in the NMR tube, surrounding the unfolded part of the stem, that appears like a large wedge shaped bright structure in the center of both Figures, is due to a significant increase of the condensed water amount and confirms that the plant continued to transpire.

As reported previously, it is rather difficult to univocally identify the top level of the stem reached by the $\mathrm{D}_{2} \mathrm{O}$, as the tracer front moving upward is not sharp. Indeed several effects such as the Hagen Poiseuille flow, the exchange between compartments and the diffusion effects smooth it out [20]. In the present study, the apex of the tracer front was identified by the analysis of the transversal profiles carried out column by column in a chosen image. At the bottom of Figs. $3 \mathrm{a}$ and $3 \mathrm{~b}$ the transversal profiles, at the stem levels indicated by an arrow, are shown. Both profiles show a double peak on the left and a broad peak on the right, corresponding to the frontal and the rear part of the folded stem respectively. The arrows indicate that the profiles cor- respond to the apex of the tracer front at two (a) and five (b) hours respectively. These levels could be identified as, when reaching the apex of the tracer front, the intensity of the tracer profile suddenly lowered, the high proton signal of the water flowing in the stem being substituted by the much lower proton signal of the isotopic impurity of the $\mathrm{D}_{2} \mathrm{O}$ tracer. It can be also observed that at any stem level the transversal profiles show the double peak on the left, indicating the absence of proton signal at the center of the stem that is the central void region already observed in Fig. 4a. In conclusion, although both the void region and the tracer front would give a dark image due to the loss of proton signal, nevertheless by the analysis of the transversal profiles the top tracer level was identified.

As already reported, a method for determining the average transport velocity of a tracer is to set the position (given as frequency values) of the tracer front in successive images. After the appropriate frequency-distance conversion the position of the tracer front can be determined as a function of time [20]. By this procedure an average $\mathrm{D}_{2} \mathrm{O}$ transport velocity $\mathrm{v}=1 \mathrm{~mm} \cdot \mathrm{h}^{-1}$ was calculated. Indeed, this low tracer transport value was ascribable to the pure $\mathrm{D}_{2} \mathrm{O}$ whose absorption kinetics is usually slowed down with respect to pure water. In fact, by replacing $\mathrm{H}_{2} \mathrm{O}$ by $\mathrm{D}_{2} \mathrm{O}$, changes in reaction and diffusion rates are rather considerable, owing to the high relative mass difference between the two isotopically different waters [28]. Moreover the extent of these changes is known to strongly depend on their relative concentrations. These findings are reported also for animal tissues. Our previous NMR studies on the anaerobic metabolism were carried out on intact excised muscles soaked in perdeutered Ringer solution $\left(\mathrm{D}_{2} \mathrm{O} / \mathrm{H}_{2} \mathrm{O}\right.$ 4: $\left.1 \mathrm{v} / \mathrm{v}\right)$. 
The proportion of $\mathrm{D}_{2} \mathrm{O}$ in the Ringer was the greatest compatible with normal metabolite kinetics, particularly for lactate production [29,30]. In the present study, the use of pure $\mathrm{D}_{2} \mathrm{O}$ allowed the water caused by plant transpiration to become clearly visible and the position of the tracer front to be well identified. Nevertheless this concentration probably did not allow normal tracer uptake by the roots and flow in the plant stem. Moreover it is well known that water flow in plants mainly depends on environmental parameters such as temperature, humidity, illumination and aeration. A correlation between the evaporation rate of the water from 6 days old castor bean seedlings and the relative humidity is reported in the literature: a relative humidity of $100 \%$ would stop transpiration and flow almost completely [17]. Indeed for our samples, the relative humidity was 50\% at the onset of the kinetics, but increased during the experiment, owing to the little exchange surface between the uncapped NMR tube and the surroundings. Therefore the poor illumination and the high humidity did not allow a normal tracer uptake and transpiration. These last are the major causes of the extremely slow rates of transpiration and consequently of the estimated slow tracer transport velocity. However the amount of condensed water shown in Fig. 3a that greatly increased in Fig. $3 \mathrm{~b}$ proved that not all stomata were closed and the transpiration pathway existing through the leaf surface would not be completely interrupted. Thus it can be concluded that the forces driving the flow were present but probably the tracer flow resulted slowed down by both the tracer concentration and the aforementioned environmental conditions.

Fig. 4b shows the spin-echo transversal image of the stem at thirty hours at the same stem level of Fig. 4a as indicated by the arrow in the sketch. The image was acquired using a receiver gain of 800 , instead of 200, as the proton water signal was almost completely lost. Thus $30 \mathrm{~h}$ later, the $\mathrm{D}_{2} \mathrm{O}$ tracer had reached the upper part of the stem. From the image it appears that not only the vasculature, but also almost all surrounding regions are dark, indicating that the tracer was flowing both axially upward in the vascular bundle, and radially through the stem tissues. Only the cortical layer is still visible. Thus the conclusion could be drawn that the $\mathrm{D}_{2} \mathrm{O}$ does not only flow vertically upward, but that a radial mechanism of water transport also occurs.

\subsubsection{Gadolinium transport in Morning Glory stem}

Before $\mathrm{t}=0$, the roots of a Morning Glory plant were immersed in pure water. At $\mathrm{t}=0$, the intact plant was carefully introduced in the NMR tube and the roots immersed in $0.5 \mathrm{~mL}$ of Gd-DTPA solution (see Section 2.1), previously located at the bottom of the NMR tube. The kinetics of Gd tracer uptake was followed for thirty hours.

The interaction of molecules with paramagnetic ions is known to cause an increase in the relaxation rates by shortening both $T_{1}$ and $T_{2}$. In the present study Gadolinium chelates enhance the relaxation mechanisms mainly of tissue water, proportionally to the ion concentration $[5,18]$.
Thus by spin-echo MRI experiments water signal can be increased or decreased by using short TR or long TE values respectively. In the present study a good planar resolution was achieved by using a relatively long echo time (TE $=$ $12.7 \mathrm{~ms}$ ). Thus a low Gd concentration of $100 \mu \mathrm{M}$ was chosen to reduce the loss of water signal resulting from the shortening of $\mathrm{T}_{2}$ and to guaranty an increase in the proton signal through $\mathrm{T}_{1}$ weighted images while following the paramagnetic ion uptake. Therefore $\mathrm{T}_{1}$-weighted MRI experiments could distinguish the $\mathrm{Gd}$ tracer absorbed by the roots from the water initially present in the plant stem.

Test experiments were previously carried out on a phantom consisting of a $10 \mathrm{~mm}$ NMR tube filled with pure water, containing a coaxial $5 \mathrm{~mm}$ NMR tube filled with $100 \mu \mathrm{M}$ $\mathrm{Gd}$ aqueous solution. Images of the phantom (not shown) were collected with the acquisition parameters used for the experiments on Morning Glory samples, by changing only the recycle time (TR). For TR $=1 \mathrm{~s}$ the maximum contrast enhancement was reached between the tube containing the pure water and the inner tube containing the Gd solution.

Fig. 5 shows the longitudinal xz spin-echo images (no slice selection) collected at two (a) and five hours (b) from the beginning of the experiment. The sketch drawn in the middle of the Figure reports the plant located in the NMR tube, showing the amount of Gadolinium solution at the bottom of the tube, the roots and the lower part of the stem, that, as located inside the coil sensitive region, are observable in the images too. The sketch shows also the upper part of the stem and the leaves that are located inside the uncapped NMR tube but outside the coil sensitive region. In both images of Fig. 5, owing to the chosen contrast level, the Gd solution at the bottom of the tube and the region of the stem containing the tracer appear bright, while the part of the stem not yet reached by the tracer appears completely dark. At the bottom of Figs. 5a and 5b, the transversal profiles, at the stem level indicated by the arrow, are reported. They correspond to the top level reached by the tracer at the given time. Here the profiles result in a single peak as the stem of this sample is straight, without folding, and does not present any void in the central region (see also Figs. $6 \mathrm{a}$ and $6 \mathrm{~b}$ ). Thus, as for the $\mathrm{D}_{2} \mathrm{O}$ tracer, the stem level reached by the $\mathrm{Gd}$ front was determined by analyzing the transversal profiles column by column in the image. Indeed, in correspondence of the apex of the tracer front, the profile signal intensity suddenly increased since it passed from the region where water was flowing (low $\mathrm{T}_{1}$ weighted proton signal) to the region where $\mathrm{Gd}$ was flowing (high $\mathrm{T}_{1}$ weighted proton signal). By following the calculation procedure adopted for the $\mathrm{D}_{2} \mathrm{O}$ tracer (see Section 3.1.2) an average Gd-DTPA transport velocity $\mathrm{v}=0.7 \mathrm{~mm} \cdot \mathrm{h}^{-1}$ was calculated. This low value, similar to that calculated for the $\mathrm{D}_{2} \mathrm{O}$ tracer, is mainly to be ascribed to the high molecular weight (MW $=743$ ) of the chelated Gd molecule. It should be emphasized that the transport velocity of Gd-DTPA and not of water, probably higher, was measured. Moreover the same remarks made in the previous section (see Section 


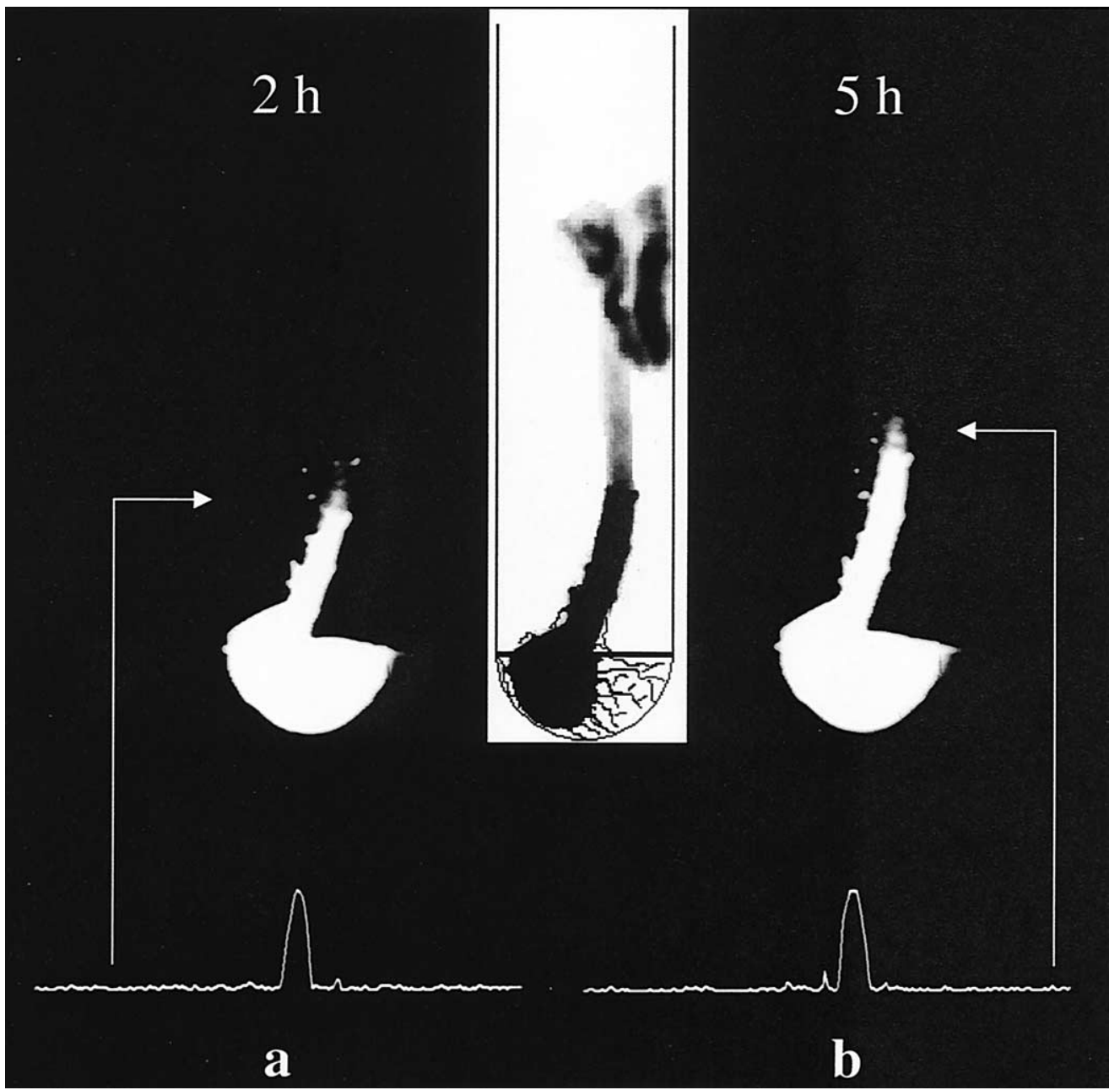

Fig. 5. Axial molecular transport component in the stem of a living Morning Glory visualized by MRI using Gd-DTPA tracer absorbed by the roots. The Gd tracer (white region) progresses upward through the stem after its absorption by the roots. The sketch drawn in the middle of the Figure shows the plant located in the NMR tube: cotyledon, roots, stem and leaves. A continuous line indicates the top of the Gd-DTPA tracer amount in the NMR tube in correspondence of the meniscus of the tracer in the images. Spin-echo images collected during the kinetics of Gd uptake: longitudinal xz images (no slice selection) collected at two hours (a) and at five hours (b): $256 \times 256$ matrix; FOV $=40 \mathrm{~mm}$; NE $=8$; RG $=4$; TE $=12.7 \mathrm{~ms}$; planar resolution: $156 \times$ $156 \mu \mathrm{m}^{2}$ At the bottom of the Figure the transversal profiles at the top level reached by the Gd tracer front are also shown. The stem is a single peak.

3.1.2.) concerning environmental parameters like poor illumination, high humidity and low aeration must be taken into account in evaluating the causes of the assessed low transport velocity.

Fig. 6 shows the spin-echo xy images collected at the same time (thirty hours) at two different stem levels. An arrow starting from the sketch (the same of Fig. 5) shown in the middle of the Figure indicates the stem levels of Fig. $6 \mathrm{a}$ and Fig. $6 \mathrm{~b}$ respectively. Looking at the sketch, it can be pointed out that the slice of Fig. $6 \mathrm{a}$ is the section of a low part of the stem, while the slice of Fig. $6 \mathrm{~b}$ is the section of an upper part of the stem. Both images show the four bright vascular bundles assuring that the Gd front advanced in the axial upward direction with respect to the stem levels reached at two (Fig. 5a) and five (Fig. 5b) hours respectively. Moreover the surrounding tissue was reached by the tracer, in particular the central pith parenchyma of Fig. 6a, confirming that a radial water transport mechanism exists.
Difference in image contrast can be noticed between parenchymal and vascular tissues as well as between endodermis and cortical parenchyma cells mainly due to difference in the relaxation times among tissues. In conclusion the use of $\mathrm{Gd}$ as tracer molecule highlighted the presence of both radial and axial water transport pathways.

\subsection{Analysis of tracer motion in the stem of Morning Glory}

\subsubsection{Parabolic tracer front formed by axial and radial tracer transports in plant stem}

MRI and optical images (see Fig. 2) assured that, like in a primary eustele, the vascular bundle of a Morning Glory stem is localized around the central pith parenchyma that sometimes becomes void in proximity to the stem apex.

Images collected during the $\mathrm{D}_{2} \mathrm{O}$ and $\mathrm{Gd}$ uptake kinetics well evidenced an axial transport mechanism (see Figs. 3 


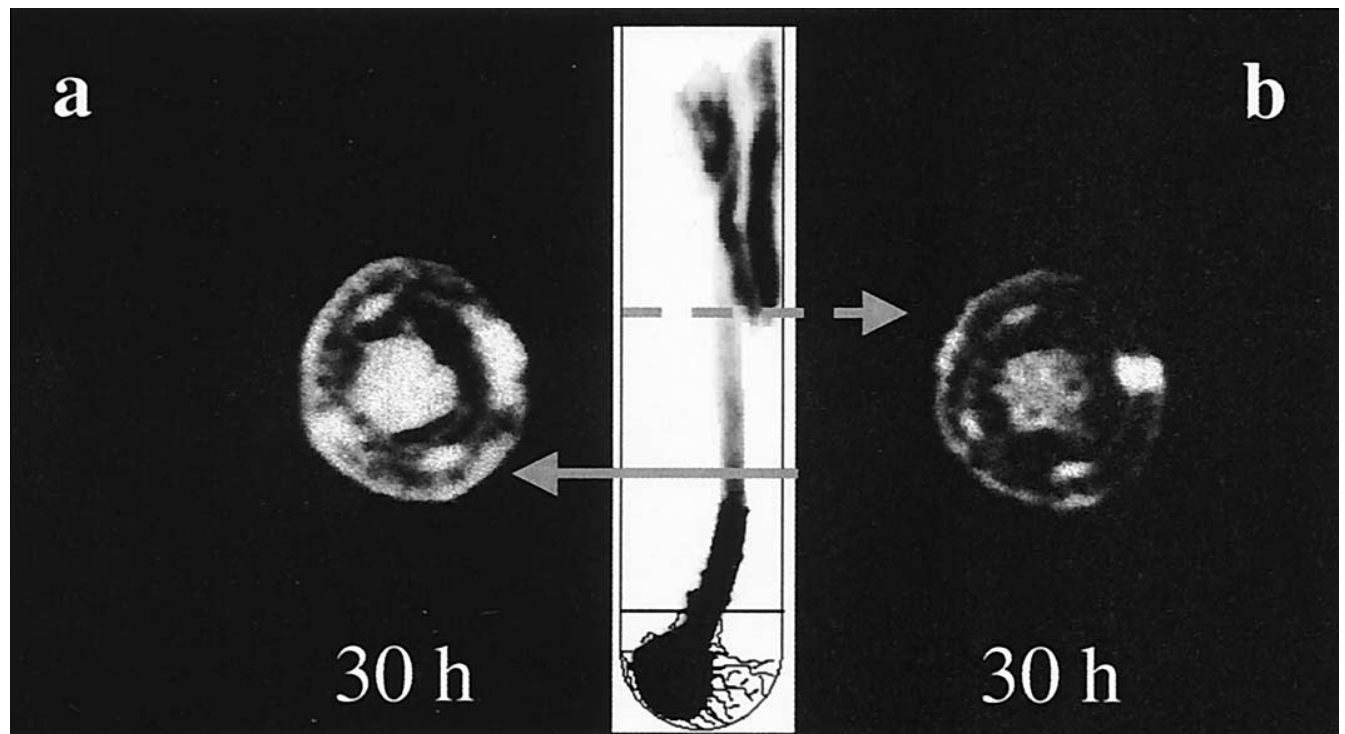

Fig. 6. Radial molecular transport component in the stem of a living Morning Glory visualized by MRI using Gd tracer absorbed by the roots. The sketch shown in the middle of the Figure (the same of Fig. 5) shows the plant in the tube. Transverse xy images collected: at thirty hours at the stem level indicated by a continuous line (a) and a dotted line (b) arrow: $256 \times 256$ matrix; FOV $=11 \mathrm{~mm}$; TE $=12.71 \mathrm{~ms}$; $\mathrm{NE}=8$; RG $=4$; voxel resolution: $43 \times 43 \times$ $3000 \mu \mathrm{m}^{3}$

and 5). The tracer absorbed by the roots, flowed in a vertical direction through the vascular tissue. Indeed through MRI experiments the axial transport through the vascular tissue was recognized as the progress of the tracer front from the time $(t>0)$ the roots absorbed the tracer instead of water. Beside the axial transport, a radial molecular transport from the vascular tissue toward the surrounding parts of the stem showed up mainly from Figs. 4 and 6. The diffusion of the water and the tracer from the vascular bundle through the stem tissue in the radial direction was expected. In fact the presence of the Brownian motion and water diffusion in plant cells was confirmed by NMR [6,21]. Moreover it was reported that small vessels might contribute significantly to radial water transport into surrounding tissue. In fact small vessels exhibit high resistance to axial flow and relative low resistance to radial flow [31].

The progress of the tracer through the vascular bundle was recognized as a cone -shaped peak, henceforth referred to as parabolic tracer front (PTF). Fig. 7 shows the PTF that consists of a peak position and a parabolic tail. The tracer front observed in Figs. 3, 4, 5 and 6 comprises an axial front at the peak position and a radial front at the width of the parabolic tail. Analysis of the PTF suggests here that in the stem there are two molecular transport mechanisms in the axial and radial directions.

In order to design a model describing the two kinds of molecular transports the following assumption have been made:

i) both the stem and the vascular tissue are straight cylindrical, coaxial tubes;

ii) the parabolic tail of the PTF has cylindrical symmetry as shown in Fig. 7, where the stem coordinates $\mathrm{z}$ and $\mathrm{r}$ are the axial and radial directions;

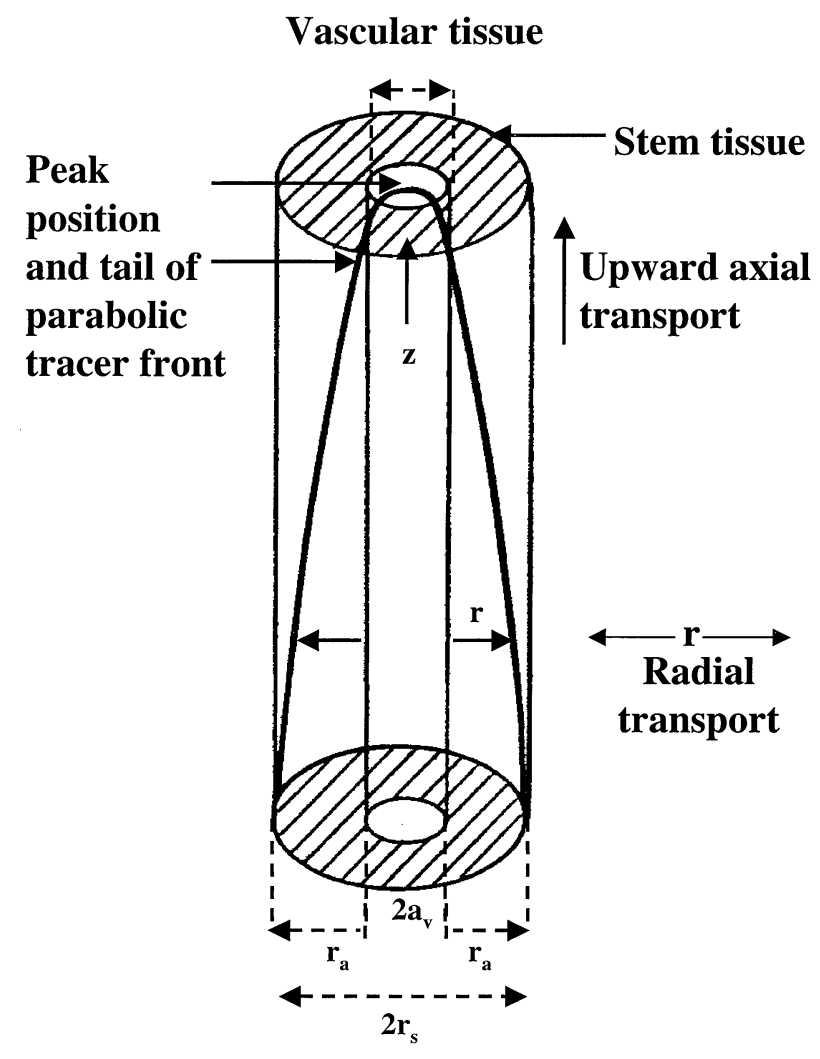

Fig. 7. Scheme of the parabolic tracer front (PTF) in the plant stem. The motion of the peak position is determined by the axial tracer transport component ( $\mathrm{z})$, and the width of the parabolic tail is determined by the radial transport component ( $r$ ). In the figure and in the text, $\mathbf{r}$ indicates the vector of radial transport while a indicates a scalar value. Following such criteria it results:

$2 \mathrm{a}_{\mathrm{v}}$ : diameter of the vascular bundle;

$r_{a}$ : the radial transport vector between the boundary surface of the vascular bundle $\left(a_{\mathrm{v}}\right)$ and the boundary surface of the stem $\left(\mathrm{a}_{\mathrm{s}}\right)$;

$\mathrm{r}_{\mathrm{s}}$ : the maximal value assumed by the radial transport vector when it reaches the boundary surface of the stem. 
iii) the vascular tissue responsible for the axial water transport is localized on the central axis of the stem at $r=0$. The central pith parenchyma is neglected;

iv) the diameter of a single vascular bundle is very small (about $100 \mu \mathrm{m}$ ) if compared to that of the stem (about $2 \mathrm{~mm}$ );

v) the stem tissue surrounding the vascular tissue has a uniform structure, that is, the diffusion coefficient (D), representing the diffusion motion of water molecules, and the hydraulic conductivity $(\kappa)$, representing the permeation of water molecules, are uniform throughout the stem tissue.

At $\mathrm{t}=0$, the upward motion of the tracer front due to the axial transport through the vasculature starts at $\mathrm{z}=0$ at constant velocity $v$. The height of the tracer front increases with an increase of $\mathrm{z}$. Coordinates $\mathrm{r}$ and $\mathrm{z}$ are measured in $\mathrm{m}$, time $\mathrm{t}$ and velocity in $\mathrm{s}$ and $\mathrm{m} / \mathrm{s}$, respectively.

Diffusion of the tracer starts from the vascular bundles at $\mathrm{t}=0$ and $\mathrm{z}=0$, and expands the width $\mathrm{r}_{\mathrm{d}}$ of the tracer front with cylindrical symmetry. At $z=0$, the radial position $r_{d}$ of the width of the tracer front is given by:

$$
r_{\mathrm{d}}=(2 \mathrm{D} \mathrm{t})^{1 / 2}
$$

The start of the diffusion from the vascular tissue is delayed at heights $\mathrm{z}>0$ since the axial tracer front arrives at such heights at $\mathrm{t}=\mathrm{z} / \mathrm{v}$ so that diffusion starts at $\mathrm{t}=\mathrm{z} / \mathrm{v}$. In the stem for $\mathrm{v} \mathrm{t}>\mathrm{z}>0$, where the tracer front has already passed, $r_{d}$ is given by:

$$
r_{\mathrm{d}}=(2 \mathrm{D}(\mathrm{t}-\mathrm{z} / \mathrm{v}))^{1 / 2}
$$

Therefore, the form of the PTF can be expressed by a parabolic curve as:

$$
z=v t-v r_{\mathrm{d}}^{2} /(2 \mathrm{D})
$$

Thus, in the stem the axial water transport and the diffusion motion of tracer molecules form the PTF for $\mathrm{t}>0$, as observed in Figs. 3, 4, 5, 6.

Besides molecular diffusion, permeation across plant cells has the potential to cause radial water transport in the stem since water transport across plasma membrane is mediated by water channels: narrow pores which allow for the passage of water across the cell membrane [32]. Therefore, a permeable water flow from the vascular tissue toward the stem surface is expected in the plant stem so as to expand the width $r_{p}$ of the tracer front if the pressure in the vascular bundle is greater than that around the stem surface. We assumed that the vascular tissue radially discharges water including the tracer at a flow rate of $\mathrm{Q} \mathrm{m}^{3} / \mathrm{s}$ per unit length for $t>0$ and the discharged tracer is endowed with the radial transport velocity $v_{r}(r)$ which is a function of the radial position $r$, as shown in Fig. 7. Conservation of the tracer relates $\mathrm{v}_{\mathrm{r},} \mathrm{r}$ and $\mathrm{Q}$ as $2 \pi \mathrm{r} \mathrm{v}_{r}=\mathrm{Q}$. Therefore, the radial transport velocity $v_{r}(r)$ and the radial position $r_{p}$ of the width of the tracer front can be expressed as:

$$
v_{\mathrm{r}}(\mathrm{r})=\mathrm{Q} /(2 \pi \mathrm{r})
$$

where:

$$
d r_{\mathrm{p}} / \mathrm{dt}=\mathrm{v}_{\mathrm{r}}(\mathrm{r}) .
$$

Then:

$$
r_{\mathrm{p}}^{2}-\mathrm{a}_{\mathrm{v}}^{2}=(\mathrm{Q} / 2 \pi) \mathrm{t}
$$

where $2 \mathrm{a}_{\mathrm{v}}$ corresponding to $2\left(\mathrm{r}_{\mathrm{s}}-\mathrm{r}_{\mathrm{a}}\right)$ is the diameter of the vascular bundle and $2 \mathrm{a}_{\mathrm{s}}$ is the diameter of the stem, as shown in Fig. 7 and defined in the caption. The water pressure $\mathrm{p}(\mathrm{r})$ in the plant stem is a function of radial position $\mathrm{r}$. When a radial pressure gradient $\mathrm{dp} / \mathrm{dr}$ exists, the radial water transport $\mathrm{v}_{r}=\left(\mathrm{dr}_{\mathrm{p}} / \mathrm{dt}\right)$ is formed as permeable flow, obeying Darcy's law [33] and expressed as:

$$
d r_{\mathrm{p}} / \mathrm{dt}=-\kappa \mathrm{dp} / \mathrm{dr}
$$

where $\kappa$ is the hydraulic conductivity. When $\kappa$ is uniform throughout the stem tissue, the pressure $p$ at the position $r_{p}$ of the width of the tracer front is derived from Eq. (6) as:

$$
d p=-(Q / 2 \pi \kappa) d r / r_{\mathrm{p}}
$$

by defining:

$$
p=p_{\mathrm{v}}
$$

the pressure at the radial level $r_{p}=a_{v}$, where $a_{v}$ corresponds to the boundary surface of the vascular bundle and:

$$
p=p_{\mathrm{s}}
$$

the pressure at the radial level $r_{p}=a_{s}$, where $a_{s}$ corresponds to the boundary surface of the stem, then $\mathrm{p}_{\mathrm{s}}$ can be derived from Eq. (7) as:

$$
p_{\mathrm{s}}=\mathrm{p}_{\mathrm{v}}-(\mathrm{Q} / 2 \pi \kappa) \log _{\mathrm{e}}\left(\mathrm{a}_{\mathrm{s}} / \mathrm{a}_{\mathrm{v}}\right)
$$

Therefore, if the pressure in the vascular tissue is greater than that around the stem surface that is $\mathrm{p}_{\mathrm{s}}<\mathrm{p}_{\mathrm{v}}$, the vascular bundles can discharge tracer and the radial position $r_{p}$ of the width of the tracer front is given by Eq. (5). When $\mathrm{r}_{\mathrm{p}}{ }^{2} \gg \mathrm{a}_{\mathrm{v}}{ }^{2}$ is satisfied, Eq. (5) is approximated as:

$$
r_{\mathrm{p}}=((\mathrm{Q} / 2 \pi) \mathrm{t})^{1 / 2}
$$

For $\mathrm{t}>0$, the tracer permeates from the vascular tissue through the stem tissue in the radial direction as shown in Fig. 7. The permeable flow of the tracer starts at $t=0$ and $\mathrm{z}=0$, and increases the radial position $r_{p}$ of the width of the tracer front. At $z=0$, the width $r_{p}$ of the tracer front is given by Eq. (8). The start of the permeable flow from the vascular tissue is delayed at heights $z>0$, since the axial tracer front arrives at such heights at $\mathrm{t}=\mathrm{z} / \mathrm{v}$ and the permeable flow starts at $\mathrm{t}=\mathrm{z} / \mathrm{v}$. In the stem for $\mathrm{v} \mathrm{t}>\mathrm{z}>0$, where the tracer front has already passed, $r_{p}$ is given by:

$$
r_{\mathrm{p}}=((\mathrm{Q} / 2 \pi)(\mathrm{t}-\mathrm{z} / \mathrm{v}))^{1 / 2}
$$

Therefore, the form of the PTF is expressed by a parabolic curve as:

$$
z=v t-v r^{2}(2 \pi / \mathrm{Q})
$$


Thus, the axial transport and the permeable flow of the tracer in the stem forms the PTF for $\mathrm{t}>0$, as shown in Fig. 7.

\subsubsection{Evaluation of axial and radial water transport by analysis of parabolic tracer front}

Since Eq. (3) and Eq. (10) were similar, both diffusion and permeation were found to contribute to the formation of the PTF. An attempt was made to extract parameters, which constitute Eq. (3) and Eq. (10), by analyzing the progression of the Gd tracer front. Assuming that the PTF was formed only by diffusion motion of the Gd-DTPA in the stem, the diffusion coefficient $\mathrm{D}=1.0 \cdot 10^{-11} \mathrm{~m}^{2} / \mathrm{s}$ was calculated.

Water diffusion coefficients in wheat grain obtained by echo attenuation were found to be half that of the free water value $[15,21]$ and those in germinating seeds of Morning Glory [22] were close to that of free water of $2.5 \cdot 10^{-9} \mathrm{~m}^{2}$ $/ \mathrm{s}$ at ambient temperature [6]. The diffusion coefficient of the Gd-DTPA in the Morning Glory stem evaluated from the PTF was found about $1 / 100$ of that of free water. The molecular sizes of $\mathrm{D}_{2} \mathrm{O}$ and $\mathrm{H}_{2} \mathrm{O}$ are similar, and smaller than that of Gd-DTPA, the molecular weights being 20, 18 and 743 respectively. Hence, the discrepancy of the diffusion coefficients among the three molecules is expected to be due to the difference in their molecular sizes.

One vascular bundle can be modeled as a series of long and slender cells rather than as one hollow duct. Neighboring plant cells exchange elements, water and molecules through channels in the cell membrane. According to the changes in the environment, metabolic activities of the plant vary the inner pressure in order to regulate the water transport velocities. While diffusion is independent of pressure as shown in Eq. (1), permeable flow is dependent on pressure gradient in the plant tissue as shown in Eq. (6). Since Eq. (3) and Eq. (10) indicate that the PTF is formed by both diffusion and permeation, and the diffusion coefficient of water in plant tissue is considered not to be affected by the environment $[3,15,21]$, the analysis of the PTF has the potential to determine the time variation of the pressure gradient in the radial direction of a plant stem, which is caused by changes in the environmental conditions surrounding the plant. Indeed, in the present study, measurements have been made under environmental conditions so that we were unable to distinguish the effects of diffusion and the pressure driven radial flow. At the same time, as it was already pointed out, the rate of transpiration and the tracer flow were extremely slowed down mainly owing to poor illumination and high humidity. Nevertheless the tracer transport mechanism through the axial and radial components could be visualized. Therefore by means of our experimental results, the analysis of the PTF can neither provide the exact concentration profile of the tracer, nor evaluate the pressure gradient in the stem tissue.

\section{Conclusions}

MRI has been applied to the study of molecular transport in living Morning Glory samples, by independently using $\mathrm{D}_{2} \mathrm{O}$ and Gadolinium chelate as tracers. The plant morphology has been characterized in a non-invasive and nondestructive way. Image analysis allowed the parenchyma tissues and the vascular bundles, both in the roots and in the stem to be visualized, as well as the presence, in some samples, of void regions in the central part of the stem. In particular, the vascular system appeared completely undifferentiated in the roots, while four vascular bundles were well visible along the stem, located between the surface and the central axis. The condensed water produced as a consequence of plant transpiration has been imaged in the experiments performed in $\mathrm{D}_{2} \mathrm{O}$ : as shown by spin-echo images, the transpired $\mathrm{H}_{2} \mathrm{O}$ was observed at the solution meniscus, in a very slow exchange regime with $\mathrm{D}_{2} \mathrm{O}$.

In the present paper, molecular transport mechanism has been investigated by analyzing the progress of tracers in the stem, as measured in spin-echo images. MRI experiments carried out on living plants growing in the magnet were combined and a model able to describe the pattern of transport in the stem built up. In the absence of internal cavities, the water transport has been interpreted on the basis of a simple model in which the parabolic tracer front (PTF), formed by the concentration profile of the tracer molecules, was rationalized in terms of axial and radial components. The tracer absorbed by the roots was axially transported through the vascular tissue and radially discharged toward the stem surface at the peak position and at the parabolic tail of the PTF respectively. Analysis of PTF revealed that the width of the parabolic tail increased as a function of the square root of time by the radial molecular transport, caused by both diffusion and permeation.

By following the kinetics of the $\mathrm{D}_{2} \mathrm{O}$ uptake an average transport velocity of $1 \mathrm{~mm} \cdot \mathrm{h}^{-1}$ was calculated. This value, low if compared to that found in experiments with $\mathrm{H}_{2} \mathrm{O}$, was mainly ascribed to the pure $\mathrm{D}_{2} \mathrm{O}$ employed and to the ambient conditions in which the plants were held, particularly poor illumination and high humidity. Nevertheless not all stomata were closed so that transpiration could occur even if at a slow rate, so that the forces driving the water flux were still present. Indeed, an average transport velocity of $0.56 \mathrm{~mm} \cdot \mathrm{min}^{-1}$ in the ivy stem and of less than $1 \mathrm{~mm}$ $\cdot \mathrm{h}^{-1}$ in the cactus were previously calculated by using the $\mathrm{D}_{2} \mathrm{O}$ tracer in a concentration $\mathrm{D}_{2} \mathrm{O} / \mathrm{H}_{2} \mathrm{O} 4: 1 \mathrm{v} / \mathrm{v}$ [20].

By following the kinetics of the uptake of $100 \mu \mathrm{M}$ Gd-DTPA aqueous solution, an average transport velocity for the Gd tracer of $0.7 \mathrm{~mm} \cdot \mathrm{h}^{-1}$ was calculated. Assuming that the width of the parabolic tail was only to be attributed to the diffusion of Gd-DTPA in the stem, a diffusion coefficient of $1 \cdot 10^{-11} \mathrm{~m}^{2} / \mathrm{s}$ was calculated for Gd-DTPA, i.e., $1 / 100$ of that of the water $\left(2 \cdot 10^{-9} \mathrm{~m}^{2} / \mathrm{s}\right)$ in plant tissue observed using proton MRI. The discrepancy in the diffusion coefficients as well as in the average transport velocity 
between Gd-DTPA and $\mathrm{H}_{2} \mathrm{O}$ in plant tissues was estimated to be mainly due to the difference in the molecular weight of the two compounds.

In the model, the analysis of the PTF revealed that the width of the parabolic tail could be attributed to diffusion as well as permeable flow due to pressure gradient in the radial direction of the stem. Indeed, by means of the results of the present paper the effects of diffusion and of pressure driven radial flow could not be distinguished so that the analysis of PTF did not allow evaluation of the pressure gradient in the plant stem. Nevertheless, comparison of the PTF under different environmental conditions surrounding the plant could suggest changes in the inner pressure of the plant. The present study clearly showed the movement of tracer molecules in plant tissue and their movement through the stem. This may prove to be a useful technique in the study of plant biology for more focused studies.

\section{Acknowledgments}

The authors M. G., F. G., A. V. and L. Z. would like to express their grateful thanks to Dr. A. Zelaschi of CNR of Milano for technical assistance, to Ing. G. Dotelli and Dr. S. Fara of Politecnico of Milano for the acquisition of the light microscopy images and to the 'Fondazione Antonio de Marco' for financial support.

\section{References}

[1] Kramer PJ. Plant water relations. New York: Academic Press, 1983.

[2] Steudle E, Peterson CA. How does water get through roots? J Exp Bot 1998;49(322):775-88.

[3] Callaghan PT. Principles of nuclear magnetic resonance microscopy. Oxford: Clarendon Press, 1991.

[4] Ratcliffe RG. In vivo NMR Spectroscopy: biochemical and physiological applications to plants. In: Shachar-Hill Y, Pfeffer PE, editors. Nuclear magnetic resonance in plant biology, Vol. 16. Rockville, Maryland U.S.A.: Am Soc of Plant Physiologists, 1996, p. 1-32.

[5] MacFall JS, Van As H. Magnetic resonance imaging of plants. In: Shachar-Hill Y, Pfeffer PE, editors. Nuclear magnetic resonance in plant biology, Vol. 16. Rockville, Maryland U.S.A.: Am Soc of Plant Physiologists 1996, p. 33-76.

[6] Chudek JA, Hunter G. Magnetic resonance imaging of plants. Progress in Nuclear Magnetic Resonance Spectroscopy 1997;31:43-62.

[7] Bacic G, Ratkovic S. Water exchange in plant tissue studied by proton NMR in the presence of paramagnetic centers. Biophys $\mathrm{J}$ 1984;45:767-76.

[8] Hills BP, Duce SL. The influence of chemical and diffusive exchange on water proton transverse relaxation in plant tissues. Magn Reson Imaging 1990;8:321-31.

[9] Sarafis V, Pope J, Sarig Y. Some aspects of NMR microscopy applications in plant science and agriculture. In: Blumich B, Kuhn W, editors. Magnetic resonance microscopy, methods and applications in materials science, agriculture and biomedicine. Weinheim: $\mathrm{VCH}$, Verlagsgesellschaft, Weinheim, 1992, 459-75.

[10] Pope JM. Application of chemical shift Microscopy to non-invasive histochemistry of plant materials. In: Blumich B, Kuhn W, editors. Magnetic resonance microscopy, methods and applications in mate- rials science, agriculture and biomedicine. Weinheim: VCH, Verlagsgesellschaft, 1992, p. 441-57.

[11] Johnson GA, Brown J, Kramer PJ. Magnetic resonance microscopy of changes in water content in stems of transpiring plants. Proc Natl Acad Sci USA 1987;84:2752-5.

[12] Gussoni M, Greco F, Consonni R, Molinari H, Zannoni G, Bianchi G, Zetta L. Application of NMR microscopy to the histochemistry study of olives (Olea europaea L.). Magn Reson Imaging 1993;11:259-68.

[13] Gussoni M, Greco F, Pegna M, Bianchi G, Zetta L. Solid state and microscopy NMR study of the chemical constituents of Afzelia cuazensis seeds. Magn Reson Imaging 1994;12(3):477-86.

[14] MacFall JS, Johnson GA. The architecture of plant vasculature and transport as seen with Magnetic Resonance Microscopy. Can J Bot 1994;72:1561-73.

[15] Xia Y, Callaghan PT. "One shot" velocity microscopy: NMR imaging of motion using a single phase-encoding step. Magn. Reson. Med 1992;23(1):138-53.

[16] Schaafsma, TJ, Van As H, Palstra WD, Snaar JEM, de Jager PA. Quantitative measurement and imaging of transport processes in plants and porous media by ${ }^{1} \mathrm{H}$ NMR. Magn Reson Imaging 1992;10:827-36.

[17] Kockenberger W, Pope JM, Xia Y, Jeffrey KR, Komor E, Callaghan PT. A non-invasive measurement of phloem, and xylem water flow in castor bean seedlings by nuclear magnetic resonance microimaging. Planta 1997;201:53-63.

[18] Quiquampoix H, Ratcliffe RG, Ratkovic S, Vucinic Z. ${ }^{1} \mathrm{H}$, and ${ }^{31} \mathrm{P}$ NMR investigation of Gadolinium uptake in maize roots. J Inorg Biochem 1990;38:265-75.

[19] Snaar JEM, Van As H. Probing water compartments and membrane permeability in plant cells by ${ }^{1} \mathrm{H}$ NMR relaxation measurements. Biophys J 1992;63:1654-8.

[20] Link J, Seelig J. Comparison of Deuterium NMR Imaging methods and application to plants. J Magn Reson 1990;89:310-30.

[21] Eccles CD, Callaghan PT, Jenner CF. Measurement of the self diffusion coefficient of water as a function of position in wheat grain using nuclear magnetic resonance imaging. Biophys J 1988;53:77-81.

[22] Isobe S, Ishida N, Koizumi M, Kano H, Hazlewood CF. Effect of electric field on physical states of cell-associated water in germinating Morning Glory seeds observed by ${ }^{1} \mathrm{H}-\mathrm{NMR}$. Biochim Biophys Acta 1999;1426:17-31.

[23] Osuga T, Obata T, Ikehira H, Tanada S, Sasaki Y, Naito H. Dialysate pressure isobars in a hollow-fiber dialyzer determined from Magnetic Resonance Imaging and numerical simulation. Artif Organs 1998; 22(10):907-9.

[24] Osuga $\mathrm{T}$, Tatsuoka $\mathrm{H}$. Effect of $1.5 \mathrm{~T}$ steady magnetic field on neuroconduction of a bullfrog sciatic nerve in a partially active state within several hours after extraction. Magn Reson Imaging 1999; 17(5):791-4.

[25] Boyer JS. Water transport in plants: mechanism of apparent changes in resistance during absorption. Planta 1974;117:187-207.

[26] Fahn A. Plant anatomy. Oxford: Butterworth-Heinemann, 1995.

[27] Bowes BG. A colour atlas of plant structure. London: Manson, 1996.

[28] Klein PD, Klein ER. Stable isotopes: origins and safety. J Clin Pharmacol 1986;26(6):378-82.

[29] Vezzoli A. La Spettroscopia di Risonanza Magnetica Nucleare applicata allo studio di processi metabolici nel muscolo scheletrico. D. Phil. Thesis, University of Milano, Italy; 1995.

[30] Vezzoli A, Gussoni M, Greco F, Zetta L, Cerretelli P. Quantitative analysis of anaerobic metabolism in resting anoxic muscle by ${ }^{31} \mathrm{P}$ and ${ }^{1}$ H MRS. Biochim Biophys Acta 1997;1322:195-207.

[31] Zimmermann U, Meinzer FC, Benkert R, Zhu JJ, Schneider H, Goldstein G, Kuchenbrod E, Haase A. Xylem water transport: is the available evidence consistent with the cohesion theory? Plant Cell Environ 1994;17:1169-81.

[32] Steudle E. Water transport across plant tissue: role of water channels. Biol Cell 1997;89:259-73.

[33] Batchelor GK. An introduction to fluid dynamics. Cambridge: Cambridge University Press. 1967, p. 174-255. 